\title{
SENSAÇÃO TÉRMICA EM DIFERENTES CENÁRIOS URBANOS DE CUIABÁ-MT
}

\author{
THERMAL SENSATION IN DIFFERENT URBAN SCENARIOS OF CUIABÁ-MT

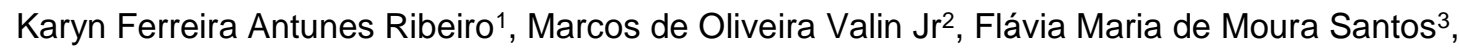 \\ Carlo Ralph De Musis ${ }^{4}$, Elio Santos Almeida Júnior ${ }^{5}$, João Basso Marques ${ }^{6}$, \\ Marta Cristina de Jesus Albuquerque Nogueira ${ }^{7}$
}

\section{RESUMO}

Em ambientes abertos como praças e parques as diferentes condições térmicas influenciam diretamente na organização e ocupação do espaço urbano e no nível de conforto dos usuários. O objetivo deste estudo foi analisar a sensação térmica em três diferentes cenários urbanos na cidade de Cuiabá-MT, com levantamento de dados meteorológicos e aplicação de questionários para verificar a preferência e percepção térmica nos cenários: sombreamento arbóreo $(\mathrm{C} 1)$, sombreamento artificial com guarda-sol (C2) e exposto ao sol (C3). Os resultados mostram que as médias das variáveis meteorológicas, temperatura do ar ( $\mathrm{Ta}$ ) e temperatura média radiante $(\mathrm{Trm})$ apresentaram diferenças significativas nos cenários. Ao realizar o cruzamento das respostas de percepção e preferência térmica nos diferentes cenários verificou-se que no $\mathrm{C} 1$ ocorreu a maior porcentagem de conforto térmico $(77,2 \%)$ aos participantes, no C2 em 31\% e no C3 ocorreu a menor porcentagem de conforto térmico (5\%), logo sendo o cenário com maior desconforto térmico (95\%). Portanto, fica explícito de quanto os indivíduos de áreas ao ar livre em Cuiabá-MT se sentem desconfortáveis termicamente, com isso este estudo corrobora com a importância e a influência do sombreamento arbóreo ou artificial nesses ambientes, que contribuem no conforto térmico e proporciona bem-estar aos pedestres.

Palavras-chave: Sombreamento arbóreo; Conforto térmico; Sombreamento artificial.

\section{ABSTRACT}

In open environments such as squares and parks the different thermal conditions directly influence the organization and occupation of urban space and the comfort level of users. The objective of this study was to analyze the thermal sensation in three different urban scenarios in the city of Cuiabá-MT, with survey of meteorological data and application of questionnaires to verify the preference and thermal perception in the scenarios: arboreal shading (C1), artificial shading with umbrella (C2) and sun exposure (C3). The results show that the averages of the meteorological variables, air temperature ( $\mathrm{Ta}$ ) and radiant average temperature (Trm) presented significant differences in the scenarios. When crossing the perception and thermal preference responses in the different scenarios it was found that in $\mathrm{C} 1$ there was the highest percentage of thermal comfort $(77.2 \%)$ to the participants, in C2 $31 \%$ and in C3 the lowest percentage of comfort occurred (5\%), thus being the scenario with the greatest thermal discomfort (95\%). Therefore, it is explicit how much individuals in Cuiabá-MT feel thermally uncomfortable in open areas, so this study corroborates the importance and influence of arboreal or artificial shading in these environments, which contribute to thermal comfort and provide well-being to pedestrians.

Keywords: Arboreal shading; Thermal comfort; Artificial shading.

Recebido em 20.05.2019 e aceito em 30.08.2019

1 Tecnólogo em Controle de Obras. Mestre em Física Ambiental. Aluna de Doutorado em Física Ambiental na UFMT e Professora no IFMT. Cuiabá/MT. Email: karyn.ribeiro@cba.ifmt.edu.br

2 Tecnólogo em Controle de Obras. Doutor em Física Ambiental. Professor no IFMT. Cuiabá/MT. Email: marcos.valin@cba.ifmt.edu.br

3 Arquiteta. Doutora em Física Ambiental. Professora na UFMT. Cuiabá/MT. Email: flavia_mms@hotmail.com

4 Engenharia Civil. Doutor em Educação. Professor na UNIC. Cuiabá/MT. Email: carlo.demusis@gmail.com

5 Ciência da Computação. Mestre em Física Ambiental. Aluno de Doutorado em Física Ambiental na UFMT. Cuiabá/MT. Email: elio_j_@hotmail.com

6 Físico. Doutor em Física Ambiental. Professor na UFMT. Cuiabá/MT. Email: jbassofisico@gmail.com

7 Engenharia Civil. Doutora em Engenharia Civil. Professora na UFMT. Cuiabá/MT. Email: mcjanp@gmail.com 


\section{INTRODUÇÃO}

As alterações térmicas que ocorrem nos ambientes urbanos podem afetar os seres humanos de diferentes maneiras, como saúde, conforto, emoções, comportamento e desempenho nas atividades diárias. Estas mudanças climáticas locais podem ser tanto positivas como negativas (ROSSI; KRÜGER, 2013).

Vários estudos sobre conforto térmico foram desenvolvidas em ambientes fechados, visto que nesses ambientes as variáveis envolvidas podem ser controladas (MONTEIRO; ALUCCI, 2010). Entretanto avaliar o conforto térmico externo nas cidades é mais complexo e há grandes variações temporais e espaciais (JOHANSSON et al., 2017), e as condições térmicas são menos estáveis. Suas áreas são heterogêneas com diferentes tipos de superfícies e materiais urbanos, gerando assim um microclima próprio (MIDDEL et al., 2016).

Liu, Zhang e Deng (2016) reforçam que o microclima ao ar livre é um fator significativo que influencia o conforto térmico externo humano, pois fatores como temperatura e umidade do ar, velocidade do vento e a radiação solar interferem diretamente na sensação térmica, alterando a percepção e a preferência térmica das pessoas (LIN et al., 2010).

Estudos sobre a influência dos parâmetros climatológicos na sensação térmica ou conforto térmico externo humano, foram analisados por vários autores recentemente (COHEN; POTCHTER; MATZARAKIS, 2013; ELNABAWI; HAMZA; DUDEK, 2016; KRÜGER; DRACH; BROEDE, 2016; ZENG; DONG, 2015). Para Hirashima (2014) a sensação térmica está intrinsecamente relacionada às trocas de calor entre o corpo e o ambiente. Nos momentos em que essas trocas ocorrem sem dificuldades, significa que o indivíduo está se sentido confortável termicamente.

Os fatores pessoais, como idade, sexo, peso, taxa metabólica e tipo de vestimenta também influenciam no conforto térmico que cada pessoa pode sentir num determinado ambiente, pois pode afetar de forma significativa nos mecanismos termorregulatórios do corpo (DAVOODI et al., 2017).

Muitos estudos sobre conforto térmico desenvolvidos no Brasil e em outros países, apresentam características semelhantes na forma de coleta em campo, por meio de coletas subjetivas (questionários) e objetivas (monitoramento microclimático), essencial na avaliação das condições de conforto térmico local (AMARAL; FONTES, 2012).

Segundo Rossi (2012), os estudos sobre conforto térmico em espaços abertos podem ser classificados em dois tipos, os que estudam a relação entre o microclima e a morfologia urbana (uso e a ocupação do solo, geometria urbana, vegetação, ventilação, dentre outros) e os que estudam a relação entre o microclima e a sensação térmica, que têm como foco a análise 
da percepção térmica por parte dos usuários e a análise do uso do espaço em função do microclima.

Estudos sobre o conforto térmico humano são fundamentais para compreender os impactos do clima e as respostas dos indivíduos as diferentes condições climáticas. Diante deste contexto, este trabalho tem como objetivo analisar a sensação térmica em diferentes cenários urbanos na cidade de Cuiabá-MT.

\section{MATERIAL E MÉTODOS}

Este estudo foi realizado na cidade de Cuiabá, capital do estado de Mato Grosso, que pertence à região Centro-Oeste do Brasil (Figura 1), com as seguintes coordenadas geográficas: $15^{\circ} 35^{\prime} 56^{\prime \prime}$ latitude Sul e $56^{\circ} 06^{\prime} 01^{\prime \prime}$ longitude Oeste. Cuiabá possui uma área de $3.538,17$ km², correspondendo $254,57 \mathrm{~km}^{2}$ à macrozona urbana e $3.283,60 \mathrm{~km}^{2}$ à área rural. Na área urbana as altitudes variam de 146 a 259 metro (SMDU, 2012).

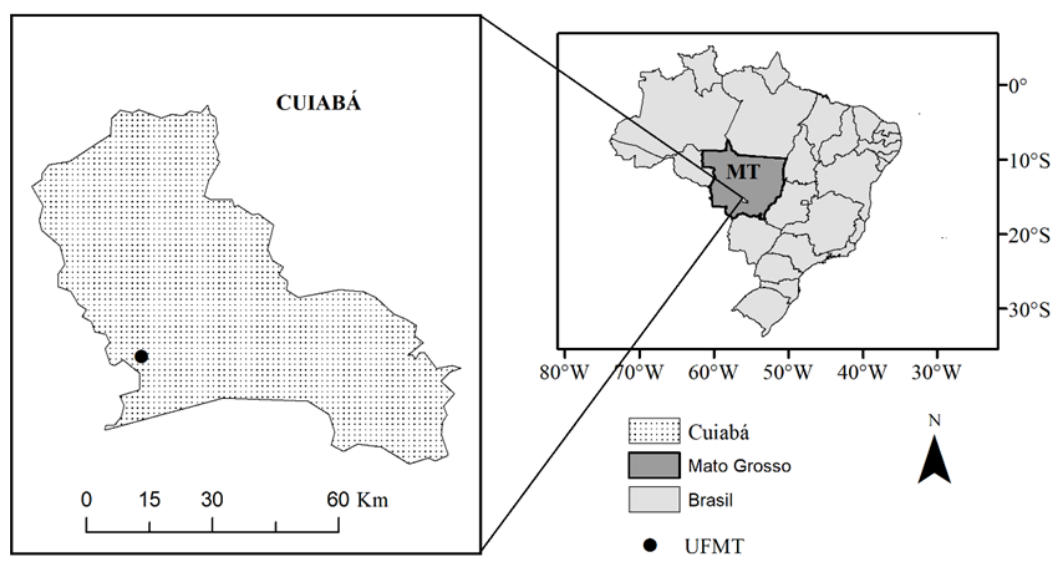

Fonte: Autores (2019)

Figura 1. Localização da cidade de Cuiabá-MT e da Universidade Federal de Mato Grosso (UFMT) que foi a área de estudo

Figure 1. Location of the city of Cuiabá-MT and the Federal University of Mato Grosso (UFMT) which was the study area

O clima de Cuiabá, de acordo com a classificação climática de Köppen é do tipo Aw (tropical úmido e típico das savanas tropicais), e o regime de precipitação apresentam dois períodos distintos: um chuvoso que engloba os meses de outubro a abril, e outro seco que ocorre nos meses de maio a setembro (CHIARANDA; COLPINI; SOARES, 2016).

A área escolhida para o estudo se localiza no Campus da Universidade Federal de Mato Grosso (UFMT), que possui aproximadamente 73 hectares, e apresenta ocupação do solo diversificada em terreno de perfil irregular (MIRANDA, 2018), dentre os quais pode-se destacar 
os locais de áreas verdes que são utilizados pelos estudantes e visitantes, para esporte e lazer (ALVES; BIUDES, 2011).

O local onde foram realizadas as coletas de dados juntamente com o preenchimento dos questionários está apresentado na Figura 2. São três cenários diferentes: cenário 1 (C1) sob as copas das árvores, cenário 2 (C2) sob guarda sol e cenário 3 (C3) exposto ao sol.
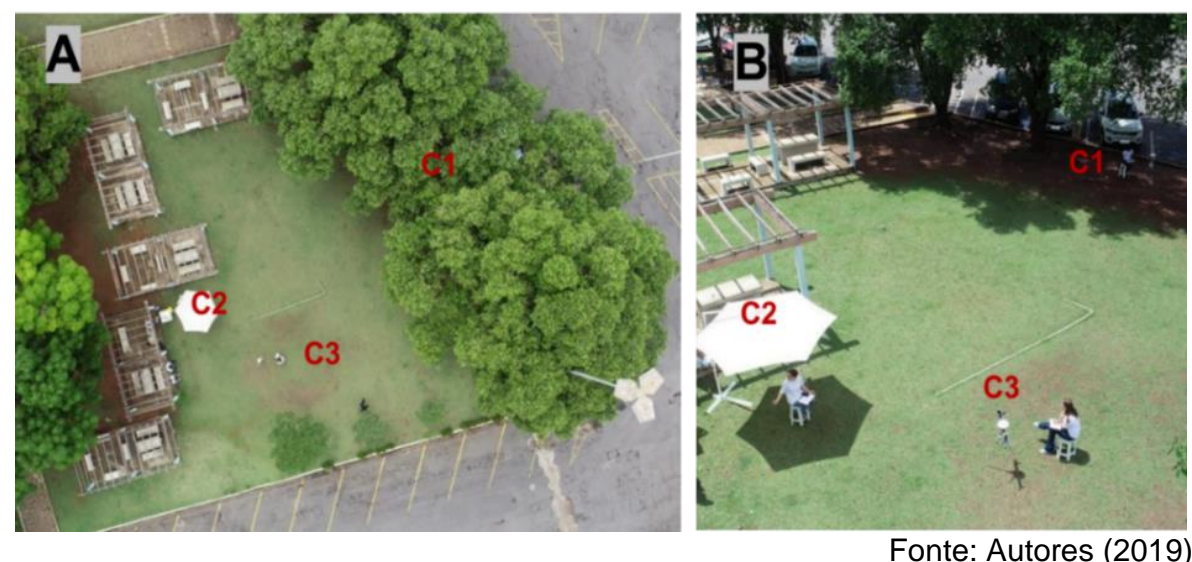

Figura 2. Localização dos pontos de coleta em diferentes ângulos (a e b). Os cenários diferentes são: cenário 1 (C1) sob as copas das árvores, cenário 2 (C2) sob guarda sol e cenário 3 (C3) exposto ao sol

Figure 2. Location of collection points at different angles ( $a$ and $b$ ). The different scenarios are: Scenery 1 (C1) under the tree tops, Scenario 2 (C2) under umbrella and Scenery 3 (C3) exposed to the sun

No C1 a espécie arbórea que a compõem é a Licania tomentosa B. (oiti), que apresenta copas densas e de grande porte. No C2, as principais características do guarda sol são: tecido $100 \%$ poliéster; possui saída de ar no topo; aberto apresenta 3,00 m de diâmetro e 2,45 m de altura. No C3 o ambiente é exposto e sua superfície de gramado.

\section{Descrições dos equipamentos utilizados}

Os sensores dataloggers utilizados foram do modelo HOBO U12-012, com cabo externo TMC20-HB. O termômetro de globo foi confeccionado para ser utilizado no canal externo do datalogger. Para verificar se os sensores estavam medindo valores semelhantes de temperatura do ar, umidade do ar e temperatura de globo, foi realizado a aferição do datalogger, utilizando a função Correlação no Windows Excel. Nesta etapa foi realizada apenas uma aferição e não a calibração dos sensores (Tabela 1). Pode-se verificar que a correlação apresentou valores próximo de 1, mostrando que os sensores estão medindo valores semelhantes e que estão aptos para serem utilizados. 
Tabela 1. Aferição dos sensores de temperatura do ar, umidade relativa do ar e temperatura de globo utilizado nos diferentes cenários

Table 1. Measurement of the air temperature, relative humidity and globe temperature sensors used in the different scenarios

\begin{tabular}{cccc|ccc|ccc} 
& \multicolumn{4}{c|}{ Temperatura do ar } & \multicolumn{3}{|c|}{ UR } & \multicolumn{3}{c}{ Temperatura de globo } \\
\hline Cenários & C1 & C2 & C3 & C1 & C2 & C3 & C1 & C2 & C3 \\
C1 & 1 & & & 1 & & & 1 & & \\
C2 & 0.997962 & 1 & & 0.996918 & 1 & & 0.999382 & 1 & \\
C3 & 0.999737 & 0.99717 & 1 & 0.999519 & 0.995377 & 1 & 0.999279 & 0.999484 & 1 \\
\hline
\end{tabular}

Para a confecção do globo foram utilizados os seguintes materiais: bola de tênis-demesa plástica de diâmetro igual a $40 \mathrm{~mm}$ e $3,7 \mathrm{~g}$ e pintada com tinta grafite claro. $\mathrm{O}$ abrigo meteorológico foi confeccionado para proteger o datalogger HOBO U12-012 utilizando os seguintes materiais: plug de esgoto; terminal de ventilação e peça antiinfiltração, todos de PVC branco, diâmetro de $100 \mathrm{~mm}$; porca sextavada de 1/4".

O termômetro de globo cinza e o abrigo, foram confeccionados a partir de informações encontradas na literatura, conforme proposto e desenvolvido por (HIRASHIMA; ASSIS, 2011) que detalha a confecção e aferição do termômetro de globo e o abrigo meteorológico.

Segundo Souza (2010) o globo cinza foi adaptado para substituir o globo negro de cobre de $0,15 \mathrm{~m}$ (ambientes internos), por superestimar a temperatura de globo, causada pela maior absorção de radiação de ondas curtas e longas, em decorrência da cor e material.

O cálculo da temperatura radiante média, foi realizada com base nos valores de temperatura de globo cinza de 40mm, utilizou-se a equação especificada pela ISO 7726 (1998), para convecção forçada (Equação 1):

$$
\operatorname{Trm}=\left[(\mathrm{Tg}+273)^{4}+\frac{1,1 \times 10^{8} \times V a^{0,6}}{\varepsilon g \times \mathrm{D}^{0,4}}(\mathrm{Tg}-\mathrm{Ta})\right]^{1 / 4}-273
$$

Onde:

Trm $=$ temperatura radiante média, em ${ }^{\circ} \mathrm{C}$,

$\mathrm{Tg}=$ temperatura de globo, em ${ }^{\circ} \mathrm{C}$,

$\mathrm{Va}=$ velocidade do $\mathrm{ar}, \mathrm{em} \mathrm{m} / \mathrm{s}$,

$\mathrm{Ta}=$ temperatura do ar, em ${ }^{\circ} \mathrm{C}$,

$\varepsilon \mathrm{g}=$ emissividade do globo, adimensional,

$\mathrm{D}=$ diâmetro do globo, em $\mathrm{m}$,

O anemômetro e o indicador da direção do vento (biruta) foram confeccionados e desenvolvidos pelo grupo de instrumentação científica do Programa de Pós-Graduação em Física Ambiental (PGFA) da UFMT. O anemômetro e a direção do vento, bem como o datalogger utilizados, foram montados em três estações utilizando placa microcontroladora Raspberry Pi 0 , os componentes GPS, Cartão SD, Led branco e os resistores Optical Encoder e Dysplay OLED.

Para o anemômetro, toda a estrutura mecânica foi desenhada em CAD e impresso em impressora 3D por extrusão. Na Figura 3 (a) apresenta o desenho em CAD 3D para impressão 
em impressora 3D por extrusão e na Figura 3 (b) as peças já impressas para o anemômetro e também os componentes: arduino nano, raspberry pi e o encoder.

Para a direção do vento todo o mecanismo foi desenvolvido, desde a placa para o circuito impresso em prototipadora de circuitos eletrônicos, a solda dos componentes como LEDs e LDR na placa e a estrutura mecânica foi desenhada em CAD e construída em impressora 3D conforme a Figura 3 (c). A estação meteorológica completa com o anemômetro, direção do vento (biruta), abrigo de PVC para proteger o datalogger e o termômetro de globo cinza, esta apresentada na Figura $3(d)$.

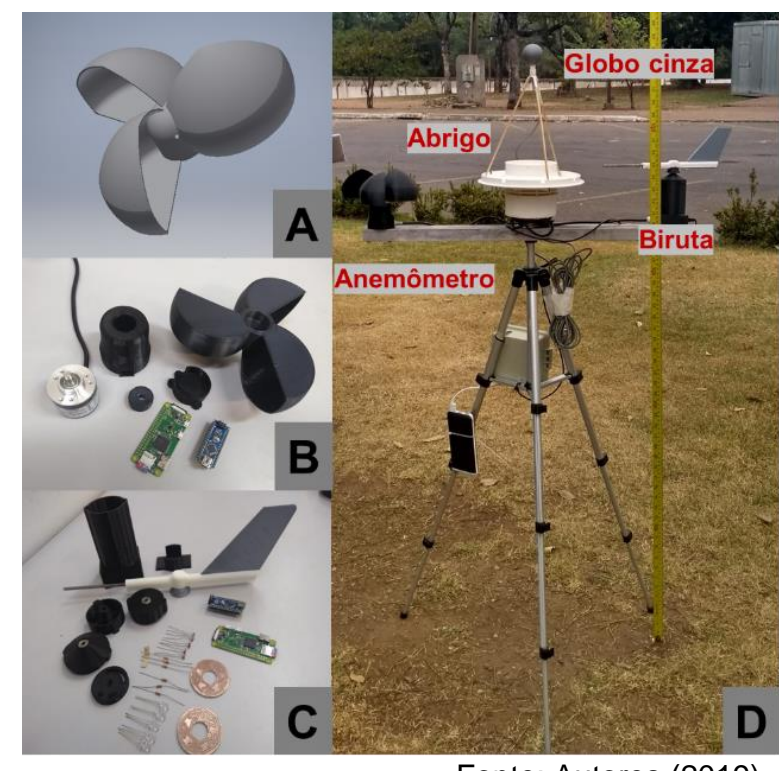

Fonte: Autores (2019)

Figura 3. Desenho em CAD do anemômetro (a), peças impressas e componentes do anemômetro (b) e peças impressas e componentes da direção do vento (c) e estação completa (d)

Figure 3. CAD design of anemometer (a), printed parts and anemometer components (b) and printed parts and wind direction components (c) and complete station (d)

Os sensores instrumentalizados de velocidade do vento foram calibrados por comparação, utilizando medidas simultâneas com um sensor ultra-sônico de alta resolução (WindSonic da marca Gill Instruments).

Foram feitas medidas em ambiente externo, similar ao ambiente de estudo, com todos os sensores desenvolvidos de velocidade e direção do vento, bem como o sensor de referência. Os dados obtidos foram comparados através de regressão linear para obter os coeficientes da curva para ajustar as medidas dos sinais do sensor a velocidade do vento, para cada sensor obtivemos uma curva (Figura 4). 


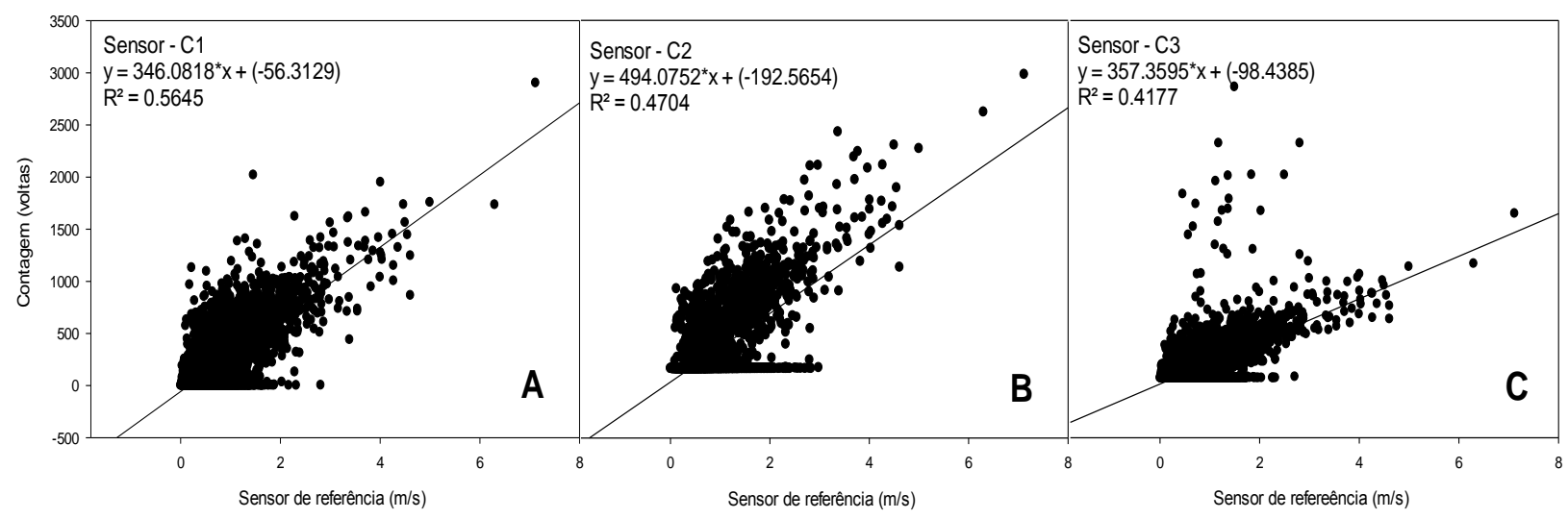

Figura 4. Regressão linear dos dados do sensor de referência (sônico) pelo sensor 3D feita para os três anemômetros construídos, utilizados nos diferentes cenários: (a) sensor do cenário 1, (b) sensor do cenário 2 e (c) sensor do cenário 3

Figure 4. Linear regression of the reference sensor data (sonic) by the 3D sensor made for the three anemometers constructed, used in the different scenarios: (a) sensor of scenario 1, (b) sensor of scenario 2 and (c) sensor of scenario 3

Para avaliar o desempenho do anemômetro 3D foram adotadas três medidas de quantificação do erro. São elas: o Erro Médio Quadrático (RMSE), o Erro Médio Absoluto (MAE) e o Desvio das Médias (MBE). Foi avaliado também pelo coeficiente de Willmott (d). Foi utilizado o software IRENE para obtenção desses resultados.

Tabela 2. Erro Médio Quadrático (RMSE), Erro Médio Absoluto (MAE), Desvio das Médias (MBE) e Coeficiente de Willmott (d) entre as medidas obtidas com sensor de referência (sônico) e o anemômetro desenvolvido em 3D

Table 2. Root Mean Square Error (RMSE), Mean Absolute Error (MAE), Mean Bias Error (MBE) and Willmott's Coefficient (d) between closing measurements obtained with reference sensor (sonic) and anemometer developed in 3D

\begin{tabular}{cccc}
\hline & $\begin{array}{c}\text { Sensor do } \\
\text { C1/Sônico }\end{array}$ & $\begin{array}{c}\text { Sensor do } \\
\text { C2/Sônico }\end{array}$ & $\begin{array}{c}\text { Sensor do } \\
\text { C3/Sônico }\end{array}$ \\
\cline { 2 - 4 } RMSE & 0.4137 & 0.4500 & 0.4742 \\
MBE & 0.0544 & 0.0262 & 0.0391 \\
MAE & 0.2982 & 0.3395 & 0.3240 \\
d (coeficiente de Willmott) & 0.8593 & 0.8143 & 0.7805 \\
\hline
\end{tabular}

Quanto mais próximo de zero os valores de MAE e RMSE, menor será a dispersão entre valores estimados e observados. De acordo com Ulgen e Hepbasli (2009), o ideal para um modelo é que o valor de MBE apresente tendência a zero, o que indica consonância entre os valores observados e estimados.

Baixos valores de erro MAE $(<0.48)$ e RMSE $(<0.34)$, e um coeficiente de Willmott $(d>0.78)$, indica uma alta correspondência entre os valores obtidos com o sensor desenvolvido e o de referência.

O sensor de direção foi construído para fornecer a medida absoluta de cada posição com resolução de 12 graus, sendo desnecessário algum tipo de calibração. 


\section{Coletas de dados microclimáticos e aplicação de questionários}

As coletas foram realizadas nas seguintes datas, horários e estação do ano, conforme a Tabela 3.

Tabela 3. Data das coletas com os respectivos horários e estação de ano Table 3. Date of collections with respective times and season

\begin{tabular}{ccc}
\hline Data & Horário & Estação do ano \\
\hline $26 / 11 / 2018$ & $09 h-17 \mathrm{~h}$ & Primavera \\
$06 / 12 / 2018$ & $09-18 \mathrm{~h}$ & Primavera \\
$08 / 03 / 2019$ & $13 \mathrm{~h}-17 \mathrm{~h}^{*}$ & Verão \\
$18 / 03 / 2019$ & $08 \mathrm{~h}-12 \mathrm{~h}^{*}$ & Verão \\
$19 / 03 / 2018$ & $13 \mathrm{~h}-17 \mathrm{~h}^{*}$ & Verão \\
\hline \multicolumn{3}{c}{${ }^{*}$ Horário de verão }
\end{tabular}

Os dados microclimáticos coletados foram temperatura do ar, umidade relativa do ar, temperatura de globo, velocidade e direção do vento, registados de 1 em 1 minuto. Simultaneamente foram aplicados questionários para os participantes do estudo sobre a percepção e preferência térmicas no momento, e foram também realizadas perguntas pessoais (sexo, idade e peso).

Os entrevistados (alunos de graduação e pós-graduação da UFMT) foram convidados previamente para fazer parte da pesquisa e com intuito de padronizar a vestimenta, os participantes utilizaram camisetas na cor branca (100\% poliéster) e calça comprida. O isolamento térmico da roupa (clo) adotado foi de 0,5.

Em cada cenário ( $C 1, C 2$ e $C 3)$ o participante permaneceu sentado em banqueta (para uniformização da taxa metabólica) por $10 \mathrm{~min}$, para adaptar-se ao ambiente. Apenas nos últimos minutos da exposição dos participantes aos diferentes cenários, os participantes respondiam aos questionários. Durante o período de 1 hora, eram necessários 3 participantes, ou seja, um em cada cenário e a cada 10 minutos os participantes trocavam de cenário. No total de 1 hora, cada participante ficou em cada cenário 2 vezes.

Para atender ao objetivo geral deste estudo foram realizadas as seguintes análises:

a) Descrição estatística dos dados microclimatológicos coletados - Os dados microclimatológicos coletados foram analisados por meio dos valores da média, mínimo, máximo, desvio padrão e variância, através do software IBM SPSS 22.0. Foram realizados também análise estatística de significância entre os dados microclimatológicos e os diferentes cenários por comparações múltiplas. A homocedasticidade dos resíduos foi avaliada pelo teste de Levene, sendo detectadas diferenças significativas, por isso optou-se por um teste post hoc robusto em relação a heterogeneidade de variâncias, no caso o procedimento de Tamhane. 
b) Análise descritiva dos dados pessoais dos entrevistados - Por meio dos questionários foram realizadas perguntas pessoais, são elas: sexo, peso e idade.

c) Obtenção das categorias de sensação térmica real para os cenários - Por meio dos questionários pode-se determinar as categorias de sensação térmica real, utilizando a combinação das respostas de percepção térmica e preferência térmica, conforme realizado por Rossi e Krüger (2013). Os mesmos autores consideram que cada indivíduo avalia o ambiente térmico de forma diferente e que os fatores psicológicos e fisiológicos influenciam em suas respostas, motivo pelo qual o cruzamento dos votos de percepção e preferência foi a forma mais adequada de classificar as pessoas em cada uma das categorias de sensação térmica. As respostas foram agrupadas em três categorias de sensação térmica: (1) confortável, (2) desconforto para o calor e (3) desconforto para o frio, obtendo-se os seguintes grupos:

Tabela 4. Modelo da tabela utilizada para realizar a correlação das respostas obtidas de preferência e percepção térmica nos diferentes cenários

Table 4. Table model used to perform the correlation of the obtained answers of preference and thermal perception in the different scenarios

\begin{tabular}{|c|c|c|c|c|c|c|c|c|c|}
\hline \multirow{3}{*}{$\begin{array}{l}\text { Preferência } \\
\text { Térmica }\end{array}$} & \multicolumn{7}{|c|}{ Percepção Térmica } & \multirow{2}{*}{$\begin{array}{c}\text { Respostas } \\
(\%)\end{array}$} & \multirow{3}{*}{ Cenário } \\
\hline & -3 & -2 & -1 & 0 & 1 & 2 & 3 & & \\
\hline & $\begin{array}{c}\text { Muito } \\
\text { frio }\end{array}$ & Frio & $\begin{array}{c}\text { Leve de } \\
\text { frio }\end{array}$ & Conforto & $\begin{array}{l}\text { Leve } \\
\text { calor }\end{array}$ & Calor & $\begin{array}{l}\text { Muito } \\
\text { calor }\end{array}$ & Soma & \\
\hline $\begin{array}{c}\text { Muito mais frio } \\
(-3)\end{array}$ & & & & $\begin{array}{c}0 \\
(0 \%)\end{array}$ & $\begin{array}{c}0 \\
(0 \%)\end{array}$ & $\begin{array}{c}0 \\
(0 \%)\end{array}$ & $\begin{array}{c}0 \\
(0 \%)\end{array}$ & $\begin{array}{c}0 \\
(0 \%)\end{array}$ & \\
\hline Mais frio $(-2)$ & & & & $\begin{array}{c}0 \\
(0 \%)\end{array}$ & $\begin{array}{c}0 \\
(0 \%)\end{array}$ & $\begin{array}{c}0 \\
(0 \%)\end{array}$ & $\begin{array}{c}0 \\
(0 \%)\end{array}$ & $\begin{array}{c}0 \\
(0 \%)\end{array}$ & \\
\hline $\begin{array}{l}\text { Pouco mais } \\
\text { de frio }(-1)\end{array}$ & & & & $\begin{array}{c}0 \\
(0 \%)\end{array}$ & $\begin{array}{c}0 \\
(0 \%)\end{array}$ & $\begin{array}{c}0 \\
(0 \%)\end{array}$ & $\begin{array}{c}0 \\
(0 \%)\end{array}$ & $\begin{array}{c}0 \\
(0 \%)\end{array}$ & $\underset{c 3}{C 1, C 2}$ ou \\
\hline $\begin{array}{c}\text { Sem mudanças } \\
(0)\end{array}$ & $\begin{array}{c}0 \\
(0 \%)\end{array}$ & $\begin{array}{c}0 \\
(0 \%)\end{array}$ & $\begin{array}{c}0 \\
(0 \%)\end{array}$ & $\begin{array}{c}0 \\
(0 \%)\end{array}$ & $\begin{array}{c}0 \\
(0 \%)\end{array}$ & $\begin{array}{c}0 \\
(0 \%)\end{array}$ & $\begin{array}{c}0 \\
(0 \%)\end{array}$ & $\begin{array}{c}0 \\
(0 \%)\end{array}$ & \\
\hline $\begin{array}{l}\text { Pouco mais } \\
\text { de calor (1) }\end{array}$ & $\begin{array}{c}0 \\
(0 \%)\end{array}$ & $\begin{array}{c}0 \\
(0 \%)\end{array}$ & $\begin{array}{c}0 \\
(0 \%)\end{array}$ & $\begin{array}{c}0 \\
(0 \%)\end{array}$ & & & & $\begin{array}{c}0 \\
(0 \%)\end{array}$ & \\
\hline Mais calor (2) & $\begin{array}{c}0 \\
(0 \%)\end{array}$ & $\begin{array}{c}0 \\
(0 \%)\end{array}$ & $\begin{array}{c}0 \\
(0 \%)\end{array}$ & $\begin{array}{c}0 \\
(0 \%)\end{array}$ & & & & $\begin{array}{c}0 \\
(0 \%)\end{array}$ & \\
\hline $\begin{array}{l}\text { Muito mais } \\
\text { calor }(3)\end{array}$ & $\begin{array}{c}0 \\
(0 \%)\end{array}$ & $\begin{array}{c}0 \\
(0 \%)\end{array}$ & $\begin{array}{c}0 \\
(0 \%) \\
\end{array}$ & $\begin{array}{c}0 \\
(0 \%) \\
\end{array}$ & & & & $\begin{array}{c}0 \\
(0 \%) \\
\end{array}$ & \\
\hline Soma & $\begin{array}{c}0 \\
(0 \%)\end{array}$ & $\begin{array}{c}0 \\
(0 \%)\end{array}$ & $\begin{array}{c}0 \\
(0 \%)\end{array}$ & $\begin{array}{c}0 \\
(0 \%)\end{array}$ & $\begin{array}{c}0 \\
(0 \%)\end{array}$ & $\begin{array}{c}0 \\
(0 \%)\end{array}$ & $\begin{array}{c}0 \\
(0 \%)\end{array}$ & $\begin{array}{c}0 \\
(0 \%)\end{array}$ & \\
\hline
\end{tabular}

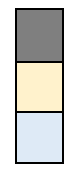

Grupo 1 = Percepção $=0$ e Preferência $=0$

Grupo 2 = Percepção $>0$ e Preferência $<0$

Grupo 3 = Percepção $<0$ e Preferência $>0$

d) Análise da relação entre sensação térmica e o efeito da radiação solar (Trm-Ta) - Foram utilizados gráficos de dispersão para analisar a relação entre as respostas de sensação térmica (confortável e desconfortável) e as variáveis meteorológicas (temperatura do ar e diferença entre temperatura radiante média e temperatura do ar). Foram observados os 
conjuntos de pontos de cada categoria e definida a faixa climática na qual está concentrada a maior parte das respostas reais de sensação térmica nos diferentes ambientes.

\section{RESULTADOS E DISCUSSÃO}

\section{Dados microclimatológicos nos diferentes cenários urbanos}

Foram calculadas estatísticas descritivas dos dados climatológicos coletados nos diferentes cenários (Tabela 5). Na maioria das variáveis (Ta, UR e Trm) os resultados apresentaram variações, com maiores diferenças de valores entre o cenário 1 e o cenário 3 . Em relação à temperatura radiante máxima, por exemplo, tem-se uma variação de $14,51^{\circ} \mathrm{C}$ (entre o C1 e C3), já a temperatura do ar máxima essa diferença foi de 1,73ํㅡ. Em contra partida a diferença entre a temperatura radiante máxima nos cenários 1 e 2 não foi expressiva $\left(0,74^{\circ} \mathrm{C}\right)$, porém na temperatura radiante média apresentou diferença evidente $\left(3,38^{\circ} \mathrm{C}\right)$.

Tabela 5. Descrição estatística da temperatura do ar, umidade relativa do ar, velocidade do vento, temperatura média radiante, temperatura média radiante-temperatura do ar (efeito da radiação) em diferentes cenários urbanos (C1, C2 e C3) de Cuiabá-MT

Table 5. Statistical description of air temperature, relative air humidity, wind speed, average radiant temperature, average radiant temperature-air temperature (radiation effect) in different urban settings (C1, C2 and C3) of Cuiabá-MT

\begin{tabular}{ccccccc}
\hline & & Média & Mínimo & Máximo & $\begin{array}{c}\text { Desvio } \\
\text { Padrão }\end{array}$ & Variância \\
\hline Temperatura & $\mathrm{C} 1$ & 33,04 & 27,53 & 36,09 & 1,90 & 3,62 \\
do ar $\left({ }^{\circ} \mathrm{C}\right)$ & $\mathrm{C} 2$ & 33,95 & 27,73 & 36,82 & 1,93 & 3,74 \\
& $\mathrm{C} 3$ & 34,71 & 27,88 & 37,82 & 1,88 & 3,54 \\
\hline Umidade & $\mathrm{C} 1$ & 57,53 & 40,87 & 80,78 & 9,24 & 3,62 \\
relativa do & $\mathrm{C} 2$ & 55,74 & 40,66 & 80,21 & 9,06 & 82,07 \\
ar $(\%)$ & $\mathrm{C} 3$ & 52,08 & 38,23 & 81,33 & 8,71 & 75,81 \\
\hline Velocidade & $\mathrm{C} 1$ & 0,98 & 0,42 & 2,26 & 0,41 & 0,17 \\
do vento & $\mathrm{C} 2$ & 0,68 & 0,58 & 1,88 & 0,24 & 0,06 \\
(m/s) & $\mathrm{C} 3$ & 0,95 & 0,55 & 1,80 & 0,32 & 0,10 \\
\hline Temperatura & $\mathrm{C} 1$ & 35,35 & 28,05 & 46,20 & 2,78 & 7,72 \\
média & $\mathrm{C} 2$ & 38,73 & 28,89 & 46,94 & 4,26 & 18,14 \\
radiante $\left({ }^{\circ} \mathrm{C}\right)$ & $\mathrm{C} 3$ & 46,98 & 30,24 & 60,71 & 6,50 & 42,22 \\
\hline Trm-Ta $^{*}$ & $\mathrm{C} 1$ & 2,31 & $-2,15$ & 10,46 & 1,71 & 2,93 \\
$\left({ }^{\circ} \mathrm{C}\right)$ & $\mathrm{C} 2$ & 4,79 & $-2,63$ & 10,77 & 3,26 & 10,63 \\
& $\mathrm{C} 3$ & 12,27 & $-2,14$ & 24,94 & 5,42 & 29,39 \\
\hline
\end{tabular}

*Temperatura média radiante-Temperatura do ar

Conforme a Tabela 6 , as variáveis climáticas nos diferentes cenários deram altamente significativas, obtido através de uma análise estatística de comparações múltiplas. Em apenas dois casos não houve diferenças significativas. O primeiro na umidade relativa do ar nos cenários sombreados (natural e artificial). O segundo na velocidade do vento nos cenários 1 e 3. 
Tabela 6. Análise estatística de significância entre os dados climatológicos e os diferentes cenários Table 6. Statistical analysis of significance between climatological data and the different scenarios

\begin{tabular}{cccc}
\hline \multicolumn{2}{c}{$\begin{array}{c}\text { Variável } \\
\text { dependente }\end{array}$} & $\begin{array}{c}\text { Significância } \\
(\mathbf{\alpha})^{*}\end{array}$ \\
\hline Temp. do ar & C1 & C2 & 0,00 \\
& & C3 & 0,00 \\
\cline { 2 - 4 } & C2 & C3 & 0,00 \\
\hline Umidade & C1 & C2 & 0,18 \\
do ar & & C3 & 0,00 \\
\cline { 2 - 4 } & C2 & C3 & 0,00 \\
\hline Vel. do & C1 & C2 & 0,00 \\
vento & & C3 & 0,91 \\
\cline { 2 - 4 } & C2 & C3 & 0,00 \\
\hline Temp. & C1 & C2 & 0,00 \\
média & & C3 & 0,00 \\
radiante & C2 & C3 & 0,00 \\
\hline Trm-Ta & C1 & C2 & 0,00 \\
& & C3 & 0,00 \\
\cline { 2 - 4 } & C2 & C3 & 0,00
\end{tabular}

${ }^{*} \alpha<0,05 \rightarrow$ Há diferença significativa; $\alpha>0,05 \rightarrow$ Não há diferença significativa

\section{Análise quantitativa dos dados pessoais dos entrevistados}

A análise quantitativa das variáveis individuais coletadas durante os levantamentos de campo, verificou-se que, com relação ao sexo dos entrevistados, há uma pequena predominância do sexo masculino com $51,7 \%$ entre os entrevistados. As maiores porcentagens da altura e do peso estão entre os intervalos de 1,60 a 1,79 m e entre 50 a 79 kg, respectivamente. Com relação à idade, predominam os entrevistados na faixa etária de 20 a 29 anos com $44,4 \%$ dos entrevistados.

\section{Sensação térmica real para diferentes cenários urbanos}

$\mathrm{Na}$ Tabela 7 estão inseridas as contagens com as porcentagens (\%) observadas do cruzamento das respostas de percepção e de preferência térmicas. Pode-se observar que no centro das tabelas estão em destaques (na cor cinza escuro) o número de pessoas que responderam estar em conforto e do lado direito na parte superior (na cor laranja claro) o número de pessoas que responderam estar se sentindo desconfortável por motivos de calor. Nesse estudo não houve desconforto por motivo de frio, localizado do lado esquerdo na parte inferior (na cor azul claro).

Conforme a Tabela 7, no cenário 1,53,3\% dos entrevistados declaram estar se sentido confortáveis e não desejaram mudanças no ambiente, porém 20,5\% responderam preferir uma condição mais fria e 3,3\% responderam estar se sentindo com leve calor. Ao realizar o cruzamento das respostas de percepção térmica e de preferência térmica, a coluna e a linha central (em cinza escuro) obtém-se que $77,2 \%$, das pessoas estão com conforto térmico e $22,8 \%$ se sentem desconfortáveis por calor nesse ambiente. 
Tabela 7. Número de respostas e porcentagens observadas sobre percepção e preferência térmicas nos diferentes cenários (C1, C2 e C3)

Table 7. Number of responses and percentages observed on thermal perception and preference in different scenarios (C1, C2 and C3)

\begin{tabular}{|c|c|c|c|c|c|c|c|c|c|}
\hline \multirow{3}{*}{$\begin{array}{l}\text { Preferência } \\
\text { Térmica }\end{array}$} & \multicolumn{7}{|c|}{ Percepção Térmica } & \multirow{2}{*}{$\begin{array}{c}\mathbf{N}^{\circ} \\
\text { Respostas } \\
(\%)\end{array}$} & \multirow{3}{*}{ Cenários } \\
\hline & \multirow{2}{*}{$\begin{array}{c}-3 \\
\text { Muito } \\
\text { frio }\end{array}$} & \multirow{2}{*}{$\begin{array}{l}-2 \\
\text { Frio }\end{array}$} & \multirow{2}{*}{$\begin{array}{c}-1 \\
\text { Leve } \\
\text { de frio } \\
\end{array}$} & \multirow{2}{*}{$\begin{array}{c}0 \\
\text { Conforto }\end{array}$} & \multirow{2}{*}{$\begin{array}{c}1 \\
\text { Leve } \\
\text { calor }\end{array}$} & \multirow{2}{*}{$\begin{array}{c}2 \\
\text { Calor }\end{array}$} & \multirow{2}{*}{$\begin{array}{c}3 \\
\text { Muito } \\
\text { calor }\end{array}$} & & \\
\hline & & & & & & & & Soma & \\
\hline $\begin{array}{c}\text { Muito mais frio } \\
(-3)\end{array}$ & & & & $\begin{array}{c}2 \\
(1,1 \%)\end{array}$ & $\begin{array}{c}0 \\
(0 \%)\end{array}$ & $\begin{array}{c}0 \\
(0 \%)\end{array}$ & $\begin{array}{c}0 \\
(0 \%)\end{array}$ & $\begin{array}{c}2 \\
(1,1 \%)\end{array}$ & \multirow{7}{*}{$\begin{array}{c}\text { Sombra } \\
\text { arbórea } \\
\text { (C1) }\end{array}$} \\
\hline $\begin{array}{c}\text { Mais frio } \\
(-2)\end{array}$ & & & & $\begin{array}{c}2 \\
(1,1 \%)\end{array}$ & $\begin{array}{c}8 \\
(4,4 \%)\end{array}$ & $\begin{array}{c}4 \\
(2,2)\end{array}$ & $\begin{array}{c}0 \\
(0 \%)\end{array}$ & $\begin{array}{c}14 \\
(7,8 \%)\end{array}$ & \\
\hline $\begin{array}{l}\text { Pouco mais } \\
\text { de frio }(-1)\end{array}$ & & & & $\begin{array}{c}33 \\
(18,3 \%)\end{array}$ & $\begin{array}{c}28 \\
(15,6 \%)\end{array}$ & $\begin{array}{c}1 \\
(0,6 \%)\end{array}$ & $\begin{array}{c}0 \\
(0 \%)\end{array}$ & $\begin{array}{c}62 \\
(34,4 \%)\end{array}$ & \\
\hline $\begin{array}{c}\text { Sem } \\
\text { mudanças } \\
(0)\end{array}$ & $\begin{array}{c}0 \\
(0 \%)\end{array}$ & $\begin{array}{c}0 \\
(0 \%)\end{array}$ & $\begin{array}{c}0 \\
(0 \%)\end{array}$ & $\begin{array}{c}96 \\
(53,3 \%)\end{array}$ & $\begin{array}{c}6 \\
(3,3 \%)\end{array}$ & $\begin{array}{c}0 \\
(0 \%)\end{array}$ & $\begin{array}{c}0 \\
(0 \%)\end{array}$ & $\begin{array}{c}102 \\
(56,7 \%)\end{array}$ & \\
\hline $\begin{array}{l}\text { Pouco mais } \\
\text { de calor (1) }\end{array}$ & $\begin{array}{c}0 \\
(0 \%)\end{array}$ & $\begin{array}{c}0 \\
(0 \%)\end{array}$ & $\begin{array}{c}0 \\
(0 \%)\end{array}$ & $\begin{array}{c}0 \\
(0 \%)\end{array}$ & & & & $\begin{array}{c}0 \\
(0 \%)\end{array}$ & \\
\hline Mais calor (2) & $\begin{array}{c}0 \\
(0 \%)\end{array}$ & $\begin{array}{c}0 \\
(0 \%)\end{array}$ & $\begin{array}{c}0 \\
(0 \%)\end{array}$ & $\begin{array}{c}0 \\
(0 \%)\end{array}$ & & & & $\begin{array}{c}0 \\
(0 \%)\end{array}$ & \\
\hline $\begin{array}{l}\text { Muito mais } \\
\text { calor (3) }\end{array}$ & $\begin{array}{c}0 \\
(0 \%) \\
\end{array}$ & $\begin{array}{c}0 \\
(0 \%)\end{array}$ & $\begin{array}{c}0 \\
(0 \%) \\
\end{array}$ & $\begin{array}{c}0 \\
(0 \%) \\
\end{array}$ & & & & $\begin{array}{c}0 \\
(0 \%) \\
\end{array}$ & \\
\hline Soma & $\begin{array}{c}0 \\
(0 \%) \\
\end{array}$ & $\begin{array}{c}0 \\
(0 \%)\end{array}$ & $\begin{array}{c}0 \\
(0 \%) \\
\end{array}$ & $\begin{array}{c}133 \\
(73,9 \%) \\
\end{array}$ & $\begin{array}{c}42 \\
(23,3 \%) \\
\end{array}$ & $\begin{array}{c}5 \\
(2,8 \%) \\
\end{array}$ & $\begin{array}{c}0 \\
(0 \%) \\
\end{array}$ & $\begin{array}{c}180 \\
(100 \%) \\
\end{array}$ & \multirow{8}{*}{$\begin{array}{l}\text { Sombra } \\
\text { artificial } \\
\text { (C2) }\end{array}$} \\
\hline $\begin{array}{l}\text { Muito mais frio } \\
(-3)\end{array}$ & & & & $\begin{array}{c}0 \\
(0 \%)\end{array}$ & $\begin{array}{c}1 \\
(0,6 \%)\end{array}$ & $\begin{array}{c}5 \\
(2,8 \%)\end{array}$ & $\begin{array}{c}3 \\
(1,7 \%)\end{array}$ & $\begin{array}{c}9 \\
(5 \%)\end{array}$ & \\
\hline $\begin{array}{l}\text { Mais frio } \\
(-2)\end{array}$ & & & & $\begin{array}{c}2 \\
(1,1)\end{array}$ & $\begin{array}{c}19 \\
(10,6 \%)\end{array}$ & $\begin{array}{c}17 \\
(9,4 \%)\end{array}$ & $\begin{array}{c}2 \\
(1,1 \%)\end{array}$ & $\begin{array}{c}40 \\
(22,2 \%)\end{array}$ & \\
\hline $\begin{array}{l}\text { Pouco mais } \\
\text { de frio }(-1)\end{array}$ & & & & $\begin{array}{c}11 \\
(6,1 \%)\end{array}$ & $\begin{array}{c}66 \\
(36,7 \%)\end{array}$ & $\begin{array}{c}11 \\
(6,1 \%)\end{array}$ & $\begin{array}{c}0 \\
(0 \%)\end{array}$ & $\begin{array}{c}88 \\
(48,9 \%)\end{array}$ & \\
\hline $\begin{array}{c}\text { Sem } \\
\text { mudanças (0) }\end{array}$ & $\begin{array}{c}0 \\
(0 \%)\end{array}$ & $\begin{array}{c}0 \\
(0 \%)\end{array}$ & $\begin{array}{c}0 \\
(0 \%)\end{array}$ & $\begin{array}{c}38 \\
(21,1 \%)\end{array}$ & $\begin{array}{c}5 \\
(2,8 \%)\end{array}$ & $\begin{array}{c}0 \\
(0 \%)\end{array}$ & $\begin{array}{c}0 \\
(0 \%)\end{array}$ & $\begin{array}{c}43 \\
(23,9 \%)\end{array}$ & \\
\hline $\begin{array}{l}\text { Pouco mais } \\
\text { de calor (1) }\end{array}$ & $\begin{array}{c}0 \\
(0 \%)\end{array}$ & $\begin{array}{c}0 \\
(0 \%)\end{array}$ & $\begin{array}{c}0 \\
(0 \%)\end{array}$ & $\begin{array}{c}0 \\
(0 \%)\end{array}$ & & & & $\begin{array}{c}0 \\
(0 \%)\end{array}$ & \\
\hline Mais calor (2) & $\begin{array}{c}0 \\
(0 \%)\end{array}$ & $\begin{array}{c}0 \\
(0 \%)\end{array}$ & $\begin{array}{c}0 \\
(0 \%)\end{array}$ & $\begin{array}{c}0 \\
(0 \%)\end{array}$ & & & & $\begin{array}{c}0 \\
(0 \%)\end{array}$ & \\
\hline $\begin{array}{c}\text { Muito mais } \\
\text { calor (3) }\end{array}$ & $\begin{array}{c}0 \\
(0 \%)\end{array}$ & $\begin{array}{c}0 \\
(0 \%)\end{array}$ & $\begin{array}{c}0 \\
(0 \%)\end{array}$ & $\begin{array}{c}0 \\
(0 \%) \\
\end{array}$ & & & & $\begin{array}{c}0 \\
(0 \%) \\
\end{array}$ & \\
\hline Soma & $\begin{array}{c}0 \\
(0 \%)\end{array}$ & $\begin{array}{c}0 \\
(0 \%)\end{array}$ & $\begin{array}{c}0 \\
(0 \%)\end{array}$ & $\begin{array}{c}51 \\
(28,3 \%)\end{array}$ & $\begin{array}{c}91 \\
(50,6 \%)\end{array}$ & $\begin{array}{c}33 \\
(18,3 \%) \\
\end{array}$ & $\begin{array}{c}5 \\
(2,8 \%) \\
\end{array}$ & $\begin{array}{c}180 \\
(100 \%)\end{array}$ & \\
\hline $\begin{array}{l}\text { Muito mais frio } \\
(-3)\end{array}$ & & & & $\begin{array}{c}0 \\
(0 \%)\end{array}$ & $\begin{array}{c}1 \\
(0,6 \%)\end{array}$ & $\begin{array}{c}6 \\
(3,3 \%)\end{array}$ & $\begin{array}{c}33 \\
(18,3 \%)\end{array}$ & $\begin{array}{c}40 \\
(22,2 \%)\end{array}$ & \\
\hline Mais frio $(-2)$ & & & & $\begin{array}{c}0 \\
(0 \%)\end{array}$ & $\begin{array}{c}10 \\
(5,6 \%)\end{array}$ & $\begin{array}{c}26 \\
(14,4 \%)\end{array}$ & $\begin{array}{c}22 \\
(12,2 \%)\end{array}$ & $\begin{array}{c}58 \\
(32,2 \%)\end{array}$ & \\
\hline $\begin{array}{l}\text { Pouco mais de } \\
\text { frio }(-1)\end{array}$ & & & & $\begin{array}{c}3 \\
(1,7 \%)\end{array}$ & $\begin{array}{c}29 \\
(16,1 \%)\end{array}$ & $\begin{array}{c}32 \\
(17,8 \%)\end{array}$ & $\begin{array}{c}12 \\
(6,7 \%)\end{array}$ & $\begin{array}{c}76 \\
(42,2 \%)\end{array}$ & \\
\hline $\begin{array}{c}\text { Sem } \\
\text { mudanças (0) }\end{array}$ & $0(0 \%)$ & $\begin{array}{c}0 \\
(0 \%)\end{array}$ & $\begin{array}{c}0 \\
(0 \%)\end{array}$ & $\begin{array}{c}3 \\
(1,7 \%)\end{array}$ & $\begin{array}{c}3 \\
(1,7 \%)\end{array}$ & $\begin{array}{c}0 \\
(0 \%)\end{array}$ & $\begin{array}{c}0 \\
(0 \%)\end{array}$ & $\begin{array}{c}6 \\
(3,3 \%)\end{array}$ & $\begin{array}{c}\text { Exposto ao } \\
\text { sol } \\
\text { (C3) }\end{array}$ \\
\hline $\begin{array}{l}\text { Pouco mais de } \\
\text { calor (1) }\end{array}$ & $\begin{array}{c}0 \\
(0 \%)\end{array}$ & $\begin{array}{c}0 \\
(0 \%)\end{array}$ & $\begin{array}{c}0 \\
(0 \%)\end{array}$ & $\begin{array}{c}0 \\
(0 \%)\end{array}$ & & & & $\begin{array}{c}0 \\
(0 \%)\end{array}$ & \\
\hline Mais calor (2) & $\begin{array}{c}0 \\
(0 \%)\end{array}$ & $\begin{array}{c}0 \\
(0 \%)\end{array}$ & $\begin{array}{c}0 \\
(0 \%)\end{array}$ & $\begin{array}{c}0 \\
(0 \%)\end{array}$ & & & & $\begin{array}{c}0 \\
(0 \%)\end{array}$ & \\
\hline $\begin{array}{l}\text { Muito mais } \\
\text { calor (3) }\end{array}$ & $\begin{array}{c}0 \\
(0 \%)\end{array}$ & $\begin{array}{c}0 \\
(0 \%)\end{array}$ & $\begin{array}{c}0 \\
(0 \%)\end{array}$ & $\begin{array}{c}0 \\
(0 \%)\end{array}$ & & & & $\begin{array}{c}0 \\
(0 \%)\end{array}$ & \\
\hline Soma & $\begin{array}{c}0 \\
(0 \%) \\
\end{array}$ & $\begin{array}{c}0 \\
(0 \%)\end{array}$ & $\begin{array}{c}0 \\
(0 \%)\end{array}$ & $\begin{array}{c}6 \\
(3,3 \%) \\
\end{array}$ & $\begin{array}{c}43 \\
(23,9 \%) \\
\end{array}$ & $\begin{array}{c}64 \\
(35,6 \%) \\
\end{array}$ & $\begin{array}{c}67 \\
(37,2 \%) \\
\end{array}$ & $\begin{array}{c}180 \\
(100 \%) \\
\end{array}$ & \\
\hline
\end{tabular}


No cenário 2 (sombra artificial), 21,1\% dos entrevistados declaram estar se sentido confortáveis e não desejaram mudanças no ambiente, porém 7,2\% responderam preferir uma condição mais fria e 2,8\% responderam estar se sentindo com leve calor. Ao realizar o cruzamento das respostas de percepção térmica e de preferência térmica, na coluna e a linha central (em cinza escuro) obteve-se que 31\% das pessoas estão com conforto térmico. Na parte superior direita da tabela que representa o desconforto para o calor, a soma das porcentagens foi de $69 \%$.

Ao comparar as porcentagens de classificação das categorias (grupo 1 e grupo 2) do cenário 1 (sombra arbórea) com o cenário 2 (sombra artificial) foi possível verificar uma diferença de 40,8\%. Indicando que o cenário arborizado possui o melhor desempenho no conforto térmico em relação ao sombreamento artificial.

No cenário 3 (exposto ao sol), apenas 1,7\% dos entrevistados declaram estar se sentido confortáveis e não desejaram mudanças no ambiente, também apenas 1,7\% responderam preferir uma condição mais fria e estar se sentindo com leve calor. Ao realizar o cruzamento das respostas de percepção térmica e de preferência térmica, a coluna e a linha central (em cinza escuro) obteve-se que somente $5 \%$ das pessoas estavam com conforto térmico. A soma das porcentagens de desconforto para o calor foi de $95 \%$.

Ao comparar as porcentagens de classificação das categorias (grupo 1 e grupo 2) do cenário 1 (sombra arbórea) com o cenário 3 (exposto ao sol) foi possível verificar uma diferença de $66,8 \%$, demonstrando a influência da arborização no conforto térmico dos entrevistados. Reforçando o que foi verificado por Streiling e Matzarakis (2003) que constataram o efeito positivo das árvores no ambiente térmico, em especial na radiação média da temperatura, e no índice térmico mostraram-se distintos entre as áreas com árvores e áreas sem árvores.

\section{Relação entre sensação térmica e efeito da radiação solar (Trm-Ta)}

Considerou-se o efeito da radiação solar como sendo a diferença entre a temperatura radiante média e a temperatura do ar (Figura 5). As diferenças de cada categoria nos distintos cenários ficaram nítidas. No cenário 1 (sombra arbórea) a categoria de desconforto está concentrada em duas faixas de temperaturas de $27,7^{\circ} \mathrm{C}$ a $31,5^{\circ} \mathrm{C}$ (pontos dispersos) e de $32,5^{\circ}$ a $36,1^{\circ} \mathrm{C}$ (pontos agrupados), os votos de conforto estão entre os valores de $27,5^{\circ} \mathrm{C}$ a $35,7^{\circ} \mathrm{C}$. $\mathrm{A}$ Trm-Ta (diferença entre a temperatura radiante média e a temperatura do ar) no cenário 1 não apresentou amplitudes elevadas, cerca de $95 \%$ variou entre $-1,7$ a $4,5^{\circ} \mathrm{C}$, em apenas 1 caso a variável foi próxima dos $7^{\circ} \mathrm{C}$.

No cenário 2 (sombra artificial) quase $90 \%$ dos votos de desconforto estão concentrados na faixa de 32 a $36,8^{\circ} \mathrm{C}$ e a amplitude do $\mathrm{Trm}$-Ta foi de $8,57^{\circ} \mathrm{C}$, ou seja, mesmo sombreado artificialmente a radiação influenciou nos dados registrados. As respostas de conforto ficaram 
dispersas, tanto na temperatura do ar como também na diferença entre a Trm e a $\mathrm{Ta}$. $\mathrm{Na}$ temperatura do ar a variação foi de 27,8 a $36,2{ }^{\circ} \mathrm{C}$ e na Trm-Ta amplitude foi de $8,14{ }^{\circ} \mathrm{C}$, ocorrendo sobreposições entre confortável e desconfortável.

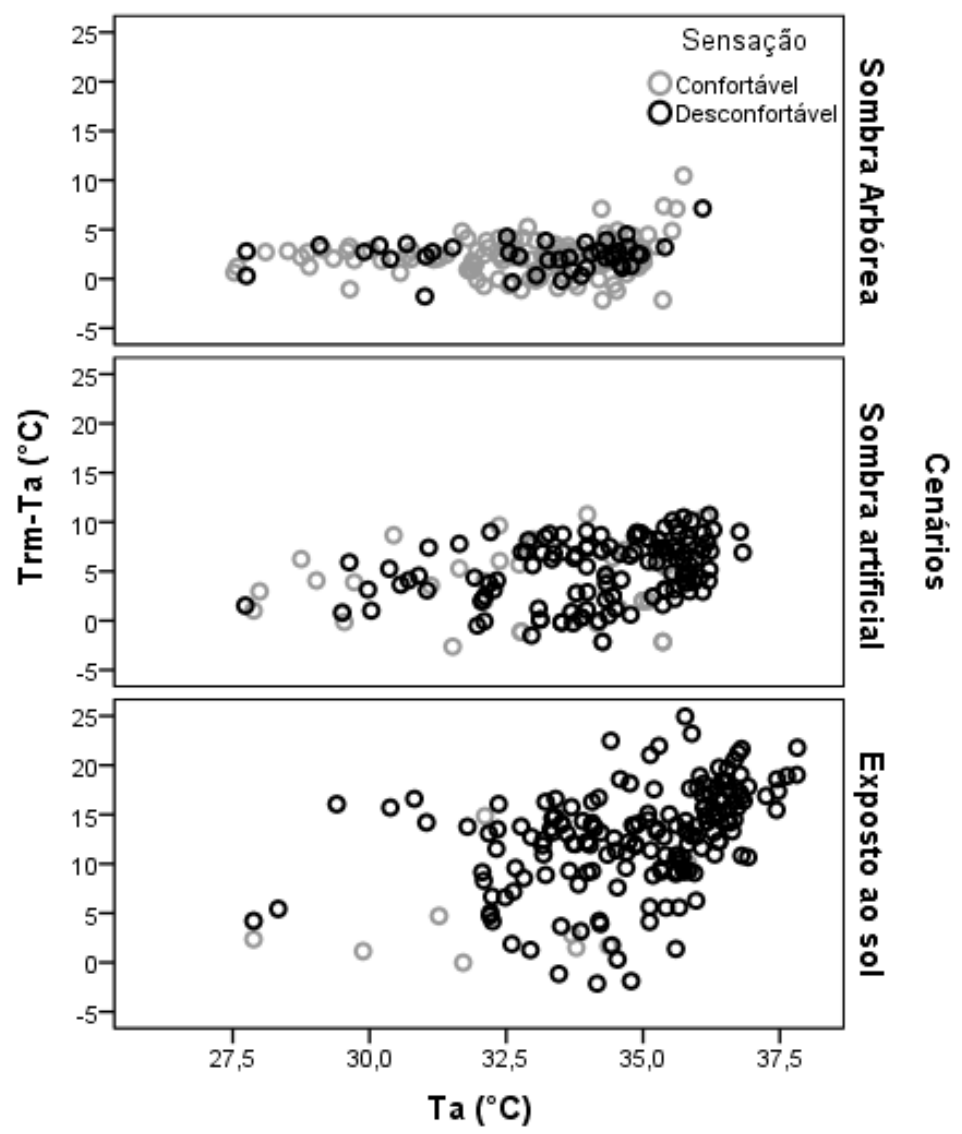

Figura 5. Conforto e desconforto em função da Ta e da diferença entre Trm e Ta da temperatura radiante média nos três cenários ( $\mathrm{C} 1, \mathrm{C} 2$ e $\mathrm{C} 3$ )

Figure 5. Comfort and discomfort responses as a function of Ta and the difference between Trm and Ta of the mean radiant temperature in the three scenarios $(\mathrm{C} 1, \mathrm{C} 2$ and $\mathrm{C} 3)$

No cenário 3 a maior parte das respostas de desconforto (89\%) está agrupada em Ta > $32,5^{\circ} \mathrm{C}$ e $73 \%$ das respostas de desconforto estão concentrados em condições de Trm-Ta superior a $10^{\circ} \mathrm{C}$, atingindo um pico máximo de $24,9^{\circ} \mathrm{C}$. Ressaltando a influência do efeito da radiação solar na sensação de desconforto térmico dos entrevistados.

No estudo realizado em Curitiba por Rossi (2012), observou-se que 77\% dos votos de desconforto para o frio e $65 \%$ dos votos de conforto ficaram concentrados em condições de Trm até $10^{\circ} \mathrm{C}$ mais alta que a Ta. Fato que ocorreu nos cenários 1 e 2, no cenário 3 a concentração foi superior ao encontrado nessa pesquisa.

As análises do efeito das variáveis climáticas (temperatura do ar e o efeito da radiação) na sensação térmica mostram que a maior influência ocorreu no cenário 3. Este resultado pode 
ser confirmado pela análise da correlação entre as variáveis climáticas e a sensação térmica (Tabela 8). A maior correlação foi na Trm-Ta com $R=0,336$.

Tabela 8. Correlações entre a sensação térmica e as variáveis: Ta e Trm-Ta

Table 8. Correlations between the thermal sensation and the variables: Ta and Trm-Ta

\begin{tabular}{|c|c|c|c|c|}
\hline & & & Ta & Trm_Ta \\
\hline \multirow{6}{*}{$\begin{array}{c}\text { Sensação } \\
\text { térmica }\end{array}$} & \multirow{2}{*}{ C1 } & $\begin{array}{l}\text { Correlação de } \\
\text { Pearson }\end{array}$ & $-0,021$ & 0,005 \\
\hline & & Sig. (2 ext) & 0,779 & 0,949 \\
\hline & \multirow[t]{2}{*}{$\mathrm{C} 2$} & $\begin{array}{c}\text { Correlação de } \\
\text { Pearson }\end{array}$ & $0,153^{*}$ & 0,143 \\
\hline & & Sig. (2 ext) & 0,040 & 0,055 \\
\hline & \multirow[t]{2}{*}{ C3 } & $\begin{array}{c}\text { Correlação de } \\
\text { Pearson }\end{array}$ & $0,297^{\star \star}$ & $0,336^{* *}$ \\
\hline & & Sig. (2 ext) & 0,000 & 0,000 \\
\hline
\end{tabular}

**. A correlação é significativa no nível 0,01 (2 extremidades).

*. A correlação é significativa no nível 0,05 (2 extremidades).

A Tabela 9 mostra as faixas da variável microclimática temperatura do ar ( $\mathrm{Ta}$ ) e a diferença entre a temperatura radiante média e temperatura do ar (Trm-Ta) para cada categoria de sensação térmica e a sobreposição das duas categorias e nos três cenários distintos analisados.

Tabela 9. Faixas climáticas por categoria de sensação térmica e sobreposição das duas categorias nas diferentes configurações

Table 9. Climatic ranges by thermal sensation category and overlap of the two categories in the different configurations

\begin{tabular}{|c|c|c|c|c|}
\hline Cenários & Variáveis & $\begin{array}{l}\text { Sensação } \\
\text { Térmica }\end{array}$ & Faixas & Sobreposição \\
\hline \multirow{2}{*}{ C1 } & $\mathrm{Ta}$ & $\begin{array}{l}\text { Conforto } \\
\text { Desconforto }\end{array}$ & $\begin{aligned} 27,5^{\circ} \mathrm{C} & \leq \mathrm{Ta} \leq 35,7^{\circ} \mathrm{C} \\
31^{\circ} \mathrm{C} & \leq \mathrm{Ta} \leq 36^{\circ} \mathrm{C}\end{aligned}$ & $31^{\circ} \mathrm{C} \leq \mathrm{Ta} \leq 35,7^{\circ} \mathrm{C}$ \\
\hline & Trm-ta & $\begin{array}{c}\text { Conforto } \\
\text { Desconforto }\end{array}$ & $\begin{array}{c}-2,1 \leq \mathrm{Trm}-\mathrm{Ta} \leq 10,4^{\circ} \mathrm{C} \\
-1,7 \leq \mathrm{Trm}-\mathrm{Ta} \leq 7,1^{\circ} \mathrm{C}\end{array}$ & $-1,7 \leq \mathrm{Trm}-\mathrm{Ta} \leq 7,1^{\circ} \mathrm{C}$ \\
\hline \multirow{2}{*}{$\mathrm{C} 2$} & $\mathrm{Ta}$ & $\begin{array}{c}\text { Conforto } \\
\text { Desconforto }\end{array}$ & $\begin{array}{c}27,7^{\circ} \mathrm{C} \leq \mathrm{Ta} \leq 36,8^{\circ} \mathrm{C} \\
31^{\circ} \mathrm{C} \leq \mathrm{Ta} \leq 36^{\circ} \mathrm{C}\end{array}$ & $31^{\circ} \mathrm{C} \leq \mathrm{Ta} \leq 36^{\circ} \mathrm{C}$ \\
\hline & Trm-ta & $\begin{array}{c}\text { Conforto } \\
\text { Desconforto }\end{array}$ & $\begin{array}{l}-2,6 \leq \mathrm{Trm}-\mathrm{Ta} \leq 10,8^{\circ} \mathrm{C} \\
-2,6 \leq \mathrm{Trm}-\mathrm{Ta} \leq 10,7^{\circ} \mathrm{C}\end{array}$ & $-2,6 \leq \mathrm{Trm}-\mathrm{Ta} \leq 10,7^{\circ} \mathrm{C}$ \\
\hline \multirow{2}{*}{ C3 } & $\mathrm{Ta}$ & $\begin{array}{c}\text { Conforto } \\
\text { Desconforto }\end{array}$ & $\begin{array}{l}27,9^{\circ} \mathrm{C} \leq \mathrm{Ta} \leq 35,8^{\circ} \mathrm{C} \\
27,8^{\circ} \mathrm{C} \leq \mathrm{Ta} \leq 37,8^{\circ} \mathrm{C}\end{array}$ & $27,9^{\circ} \mathrm{C} \leq \mathrm{Ta} \leq 35,8^{\circ} \mathrm{C}$ \\
\hline & Trm-ta & $\begin{array}{l}\text { Conforto } \\
\text { Desconforto }\end{array}$ & $\begin{array}{c}-0,02 \leq \mathrm{Trm}-\mathrm{Ta} \leq 14,8^{\circ} \mathrm{C} \\
-2,1 \leq \mathrm{Trm}-\mathrm{Ta} \leq 24,9^{\circ} \mathrm{C}\end{array}$ & $-0,02 \leq \mathrm{Trm}-\mathrm{Ta} \leq 14,8^{\circ} \mathrm{C}$ \\
\hline
\end{tabular}

Pode-se verificar que nos cenários 1 e 2 (sombra arbórea e artificial) o desconforto na Ta foi superior ao do cenário 3 (exposto ao sol), apresentando uma diferença de $3,2^{\circ} \mathrm{C}$. Mostrando a impacto que o sombreamento (natural e artificial) tem sobre a sensação térmica do pedestre. 
Já no efeito da radiação solar (Trm-ta) o desconforto apresentou uma diferença de $17,8^{\circ} \mathrm{C}$, entre os cenários 1 e 3 .

WANG et al. (2015a, 2015b) corroboraram com este estudo, onde verificaram que uma pequena infraestrutura verde (um bosque de árvores ou uma única árvore) em uma área urbana local afetou o microclima e o conforto térmico humano.

\section{CONCLUSÕES}

Os resultados apontam que a cidade de Cuiabá possui condições bioclimáticas desconfortáveis sob circunstâncias a céu aberto, devido ao efeito da radiação solar, sendo necessário utilizar estratégias bioclimáticas que contribuam na redução dos efeitos ocasionados pelo microclima local. Nesse contexto, o sombreamento arbóreo ou artificial, podem ameninar o desconforto térmico, ajudando a melhorar a sensação térmica dos indivíduos.

Este estudo corrobora com a importância e a influência da arborização urbana, que contribuem no conforto térmico e proporciona bem-estar aos seus usuários. É fundamental reforçar a necessidade da valorização, da ampliação e do potencial da vegetação em projetos urbanos pelos planejadores das cidades, com intuito de promover melhorias no conforto térmico para os pedestres.

\section{REFERÊNCIAS}

ALVES, E. D. L.; BIUDES, M. S. Os microclimas da Universidade Federal de Mato Grosso/Cuiabá. RA’E GA - O Espaco Geográfico em Análise, Curitiba, v. 23, n. 23, p. 600620, 2011.

AMARAL, C. C.; FONTES, M. S. G. DE C. Conforto térmico em corredores urbanos: estudo de caso em Bauru-SP. Paranoá: cadernos de arquitetura e urbanismo, Brasília, n. 6, p. 45-53, 2012.

CHIARANDA;, R.; COLPINI, C.; SOARES, T. S. Caracterização da bacia hidrográfica do Rio dos Cuiabá. Advances in Forestry Science, Cuiabá, n. 2357-8181, p. 13-20, 2016.

COHEN, P.; POTCHTER, O.; MATZARAKIS, A. Human thermal perception of Coastal Mediterranean outdoor urban environments. Applied Geography, United States, v. 37, n. 1, p. 1-10, 2013.

DAVOODI, F., HASSANZADEH, H., ZOLFAGHARI, A., MAEREFAT, M. Developing a new individualized 3-node model for evaluating the effects of personal factors on thermal sensation. Journal of Thermal Biology, United States, v. 69, p. 1-12, 2017.

ELNABAWI, M. H.; HAMZA, N.; DUDEK, S. Thermal perception of outdoor urban spaces in the hot arid region of Cairo, Egypt. Sustainable Cities and Society, Canada, v. 22, p. 136-145, 2016. 
HIRASHIMA, S. Q. DA S.; ASSIS, E. S. DE. Confecção e aferição de termômetro de globo e abrigo ambientes externos. In: ENCONTRO NACIONAL DE CONFORTO NO AMBIENTE CONSTRUÍDO, 11, ENCONTRO LATINO AMERICANO DE CONFORTO NO AMBIENTE CONSTRUÍDO, 7, 2011, Búzios. Anais... Búzios: ENCAC, ELACAC, 2011.

HIRASHIMA, S. Q. DA S. Percepção sonora e térmica e avaliação de conforto em espaços urbanos abertos do município de Belo Horizonte - MG , Brasil. São Paulo, 2014. 248f. Tese (Doutorado em arquitetura e urbanismo) - Universidade de São Paulo, São Paulo, 2014.

JOHANSSON, E.; YAHIA, M. W.; ARROYO, I.; BENGS, C. Outdoor thermal comfort in public space in warm-humid Guayaquil, Ecuador. International Journal of Biometeorology, United States, v. 62, n. 3, p. 387-399, 2017.

KRÜGER, E.; DRACH, P.; BROEDE, P. Outdoor comfort study in Rio de Janeiro: site-related context effects on reported thermal sensation. International Journal of Biometeorology, United States, v. 61, n. 3, p. 463-475, 2016.

LIN, T. P.; MATZARAKIS, A.; HWANG, R. L.; YING-CHE HUANG, Y. C. Effect of pavements albedo on long-term outdoor thermal comfort, Building and Environment, United States, v.45, p.213-221, 2010.

LIU, W.; ZHANG, Y.; DENG, Q. The effects of urban microclimate on outdoor thermal sensation and neutral temperature in hot-summer and cold-winter climate. Energy and Buildings, Hong Kong, v. 128, p. 190-197, 2016.

MIDDEL, A.; SELOVER, N.; HAGEN, B.; CHHETRI, N. Impact of shade on outdoor thermal comfort-a seasonal field study in Tempe, Arizona. International Journal of Biometeorology, United States, v. 60, n. 12, p. 1849-1861, 2016.

MIRANDA, S. A. DE. Sombreamento arbóreo em superfícies pavimentadas de área urbana tropical. 2018, 91f. Tese (Doutorado em Física Ambiental) - Instituto de Física, Universidade Federal de Mato Grosso, Cuiabá, 2018.

MONTEIRO, L. M.; ALUCCI, M. P. Índices de conforto térmico em espaços urbanos abertos. Fórum Patrimônio, Belo Horizonte, v. 3, n. 2, p. 1-23, 2010.

ROSSI, F. A.; KRÜGER, E. L. Comparação entre sensação térmica real e o índice PET para Curitiba/PR. In: ENCONTRO NACIONAL DE CONFORTO NO AMBIENTE CONSTRUÍDO, 12; ENCONTRO LATINOAMERICANO DE CONFORTO NO AMBIENTE CONSTRUÍDO, 8, 2013, Brasília. Anais... Brasília: ENCAC; ELACAC, 2013.

ROSSI, F. Proposição de metodologia e de modelo preditivo para avaliação da sensação térmica em espaços abertos em Curitiba. 2012, 190f. Tese (Doutorado em Tecnologia) - Programa de Pós-Graduação em Tecnologia, Universidade Tecnológica Federal do Paraná, Curitiba, 2012.

SMDU. Secretaria Municipal de Desenvolvimento Urbano. Perfil socioeconômico de Cuiabá. Cuiabá: Central de Texto, 2012.

\section{SOUZA, S. SOUZA, S. AVALIAÇÃO DO DESEMPENHO TÉRMICO NOS MICROCLIMAS} DAS PRAÇAS: PIEDADE E VISCONDE DE CAYRÚ, SALVADOR/ BA. Salvador, 2010. $203 f$. Dissertação (Mestrado em engenharia ambiental urbana) - Escola Politécnica da Universidade Federal da Bahia, Salvador, 2010. 
STREILING, S.; MATZARAKIS, A. Influence of Single Nad Small Clusters of Trees on the Bioclimate of a City.Pdf.Pdf. Journal of Arboriculture, United States, v. 29, n. x, p. 309-316, 2003.

ULGEN K., HEPBASLI A. Diffuse solar radiation estimation models for Turkey's big cities. Energy Conversion and Management, Jordan, v. 50, p. 149-156, 2009.

WANG, Y.; BAKKER, F.; DE GROOT, R.; WÖRTCHE, H.; LEEMANS, R. Effects of urban trees on local outdoor microclimate: synthesizing field measurements by numerical modelling. Urban Ecosystems, United States, v. 18, n. 4, p. 1305-1331, $2015 a$.

WANG, Y.; BAKKER, F.; DE GROOT, R.; WÖRTCHE, H.; LEEMANS, R. Effects of urban green infrastructure (UGI) on local outdoor microclimate during the growing season. Environmental Monitoring and Assessment, United States, v. 187, n. 12, p. 1-14, $2015 \mathrm{~b}$.

ZENG, Y. L.; DONG, L. Thermal human biometeorological conditions and subjective thermal sensation in pedestrian streets in Chengdu, China. International Journal of Biometeorology, United States, v. 59, n. 1, p. 99-108, 2015. 